\title{
Metallodrugs: Medicinal chemistry investigation
}

\author{
Rabiee N* \\ Department of Chemistry, Shahid Beheshti University, Tehran, Iran
}

\begin{abstract}
Metallic ions perform essential functions in natural procedures, and as well, the subject of understanding concerned along with the utility of Bioinorganic Chemistry to treatment method or early medical diagnosis of disease which can be considered as Medicinal Bioinorganic Chemistry approach. Associated with the organic/ inorganic sciences, therapeutic bioinorganic chemistry is usually still regarded as a very novel field by many, nevertheless this is certainly in contrast to the traditionally confirmed utilization of inorganic/organic/metals in pharmaceutic potions.
\end{abstract}

\section{Antimicrobial and antiparasitic approach}

A number of the primary metallodrugs utilized in remedy were definitely antimicrobial and antiparasitic agents centered on arsenic. In the early 20th, scientists examined the usage of atoxyl, arsanilic acid, intended for the medication of trypanosomiasis. Influenced by their results, another group started their study on arsenic antimicrobials that ended in the finding of salvarsan and noticeable the starting of chemotherapy. Whilst arsenicals, arsenic-based pharmaceutical drugs, had been broadly utilized in medication in the starting of the 20th, the majority of them possess replaced by much less harmful medicines. One arsenic medication which can be continue to utilized alongside trypanosomiasis at this time, in spite of its serious side effect of encephalopathy, is certainly melarsoprol, 2-(4-amino)-(4,6-diamino1,3,5-triazin-2-yl)-phenyl-1,2,3-dithiarsolan-4-methanol (Mel B, Arsobal), found out in mid-20th. The WHO sorted melarsoprol as a secondary point medication for each of those types of human being Africa sleeping ailment [1-4].

The additional couple more heavy pnictogens, antimony and bismuth, have got in therapeutic employ alongside microbes and parasites on top of that. Antimony-based medications have got been recommended vs cutaneous and mucocutaneous leishmaniasis since the parasitic transmitting of the exotic disease was first comprehended in the starting of the 20th century. The Brazilian doctor was the primary to deal with mucocutaneous leishmaniasis with antimony(III) tartar metic, potassium antimony tartrate. Soon after that, the recreation of arsenic against visceral leishmanisis was verified in Italia and India that resulted in the synthesis of an array of arsenic-containing parasitic agents, most notable the much less poisonous pentavalent antimonials: Stibosan, Neostibosan, and Ureastibamine. Additional antimony(IV) medicines adopted: sodium stibogluconate (Pentostam) and melglumine antimoniate (Glucantim or Glucantime); both keep going to become in usage at the moment in spite of their harmful side effects and raising reduction in strength because of the developing level of resistance of the parasite against antimony [5-8].

Whilst one offers to consider the toxicity alongside the restorative advantage for arsenic and antimony, bismuth is definitely non-toxic and well tolerated at substantial dosages. Since the 18th century, bismuth has been utilized internally as its subnitrate or subcitrate. The background of bismuth medications can be carefully linked to stomach disorders, however, bismuth is certainly as well coadministered in the battle against the bacterium Helicobacter pylori (They would. pylori). A L. pylori contamination may result in gastritis (type-B, bacterial), ulcers in the stomach tract, and gastric malignancy. Bismuth arrangements this kind of as colloidal bismuth subcitrate (CBS, De-Nol) or ranitidine bismuth citrate (RBC, Pylorid, Tritec) are utilized to deal with peptic ulcers that are frequently connected with $\mathrm{H}$. pylori. Clarithromycin provides the antibiotic of choice to destroy the bacterium, nevertheless its power is usually reducing with an raising level of resistance of the bacterium. This obtained level of resistance can end up being partially conquer throughout the coadministration of clarithromycin with each other with CBS or RBC only, or in mixture by way of a further antibiotic (amoxicillin) and a proton pump inhibitor (omeprazole). In the apparent bismuth-based triple therapy, bismuth subcitrate potassium (Pylera) or bismuth subsalicylate (Helidac) is definitely associated with the cocktail collectively with metronidazole and tetracycline hydrochloride. In situations wherever the couple explained first-line remedies possess failed, the quadruple therapy can become extremely effective against $\mathrm{H}$. pylori: bismuth subcitrate potassium can be given jointly with metronidazole, tetracycline, and omeprazole in one solitary capsule [9-12].

The exterior usage of tribromophenatebismuth(III), xeroform, due to its antimicrobial properties, was initial referred to at the end of the 19th century. In the previous, xeroform was frequently utilized as a alternative for iodoform in the treatment of injuries. Nowadays, occlusive petrolatum gauze easily impregnated with $3 \%$ bismuth tribromophenate is certainly offered under the name Xeroform. Bismuth-thiol substances have got been broadly analyzed for their antimicrobial properties and are presently promoted as a treatment for chronic injuries, this kind of as diabetic feet ulcers; BisEDT is usually intended to prevent the development of biofilm for advanced chronic injuries [13-16].

${ }^{\star}$ Correspondence to: Navid Rabiee, Invited Scientist, Department of Chemistry, Shahid Beheshti University, Tehran, Iran, E-mail: nrabiee94@gmail.com

Received: July 12, 2018; Accepted: July 25, 2018; Published: July 27, 2018 


\section{References}

1. Artner C (2017) DNA or protein? Capillary zone electrophoresis-mass spectrometry rapidly elucidates metallodrug binding selectivity. Chemical Communications 53: 8002-8005. [Crossref]

2. Gibaud S, Jaouen G (2010) Arsenic-based drugs: from Fowler's solution to modern anticancer chemotherapy, in medicinal organometallic chemistry. Springer 1-20.

3. Dilda PJ, Hogg PJ (2007) Arsenical-based cancer drugs. Cancer Treat Rev 33: 542-564. [Crossref]

4. Sun H (2010) Biological chemistry of arsenic, antimony and bismuth. John Wiley \& Sons.

5. Keogan DM, Griffith DM (2014) Current and potential applications of bismuth-based drugs. Molecules 19: 15258-15297. [Crossref]

6. Cangelosi VM (2010) Design considerations for the group 15 elements: The Pnictogen $\cdots$ p Interaction as a complementary component in supramolecular assembly design. Crystal Growth \& Design 10: 3531-3536.

7. Pumera M, Sofer Z (2017) 2D monoelemental arsenene, antimonene, and bismuthene: beyond black phosphorus. Advanced Materials 29: 1605299. [Crossref]

8. Nitsche C, Mahawaththa MC, Becker W, Huber T, Otting G (2017) Site-selective tagging of proteins by pnictogen-mediated self-assembly. Chem Commun (Camb) 53 : 10894-10897. [Crossref]
9. Chuah SK, Tsay FW, Hsu PI, Wu DC (2011) A new look at anti-Helicobacter pylori therapy. World J Gastroenterol 17: 3971-3975. [Crossref]

10. Gorbach SL (1990) Bismuth therapy in gastrointestinal diseases. Gastroenterology 99: 863-875. [Crossref]

11. Hansch C, Sammes PG, Taylor JB (1989) Comprehensive medicinal chemistry: the rational design, mechanistic study $\&$ therapeutic applications of chemical compounds Vol. 5: Pergamon Pr.

12. Foye WO (2008) Foye's principles of medicinal chemistry. Lippincott Williams \& Wilkins.

13. Sekhon BS (2011) Inorganics/bioinorganics: Biological, medicinal and pharmaceutical uses. Journal of Pharmaceutical Education and Research 2: 1.

14. Domenico P, Gurzenda E, Giacometti A, Cirioni O, Ghiselli R, et al. (2004) BisEDT and RIP act in synergy to prevent graft infections by resistant staphylococci. Peptides 25: 2047-2053. [Crossref]

15. Orvig C, Abrams MJ (1999) Medicinal inorganic chemistry: introduction. Chemical Reviews 99: 2201-2204. [Crossref]

16. Guo Z, Sadler PJ (1999) Metals in Medicine. Angew Chem Int Ed Engl 38: 1512-1531. [Crossref]

Copyright: (C2018 Rabiee N. This is an open-access article distributed under the terms of the Creative Commons Attribution License, which permits unrestricted use, distribution, and reproduction in any medium, provided the original author and source are credited. 